\title{
Ipratropium bromide: are patients treated with optimal therapy?
}

\author{
A.B. Millar, A. Bush, H. Al-Hillawi, J. Goldman and D.M. Denison \\ Department of Lung Function, Brompton Hospital, London SW3, UK.
}

\begin{abstract}
Summary: A double-blind crossover placebo controlled study was performed on 20 patients with stable chronic asthma, in order to obtain dose response data to ipratropium bromide $(40,80,200 \mu \mathrm{g})$ given by metered dose inhaler. The use of the $200 \mu \mathrm{g}$ dose gave a significantly greater peak effect and duration of action than the recommended standard therapeutic dose of $\mathbf{4 0} \mu \mathrm{g}$. There were marked individual variations in response to higher doses. Maximum response detected by spirometry occurred within 24 hours of inhalation, thus patients likely to gain clinical benefit are readily identified. The higher dose was well tolerated by most patients and may have clinical application in the treatment of patients who do not respond to the standard dose regime.
\end{abstract}

\section{Introduction}

Ipratropium bromide is widely used for the treatment of asthma and chronic airflow obstruction. The standard dose of $40 \mu \mathrm{g}$ administered by metered dose inhaler has been shown to be effective in these diseases. ${ }^{1-3}$ It has also been used in a nebulised form $^{4-6}$ and in combination with $\beta_{2}$ agonists. ${ }^{7,8}$ More recent work has suggested that a greater and more prolonged response may be produced with higher doses. ${ }^{1,4,9}$ This study was intended to determine the dose response to ipratropium bromide and the clinical acceptability and benefit of higher than standard therapeutic doses.

\section{Materials and methods}

Twenty chronic stable asthmatics (4 male) took part in this study (mean age \pm s.d., $51 \pm 17$ years). These patients were all known to demonstrate at least $20 \%$ reversibility in forced expiratory volume in 1 second $\left(\mathrm{FEV}_{1}\right)$ to salbutamol by inhalation and had no exacerbations of their asthma requiring therapeutic changes in the previous 6 months. All were competent users of metered dose inhalers. All were non-smokers. Their baseline forced expiratory volume (FEV) (mean \pm s.d. \% predicted) was $47 \pm 16 \%$. The subjects were each studied on four separate days. Each patient was assessed on arrival on each study day. Spirometry was performed using a dry wedge spirometer and the best of three

Correspondence: A.B. Millar, M.D., M.R.C.P., 5th Floor, Jules Thorn Building, Middlesex Hospital, Mortimer Street, London W1N 8AA, UK.

Accepted: 12 July 1990 readings was noted. No greater than $10 \%$ difference was accepted in baseline measurements between each day. All bronchodilator therapy was discontinued 12 hours prior to administration of the trial drug on each investigation day but thos patients taking concomitant steroid therapy con tinued to do so. The subjects received in double blind random order one of the following via two inhaled puffs from metered dose inhaler, (a) placebo; (b) $40 \mu \mathrm{g}$ ipratropium bromide; (c) $80 \mu \mathrm{g}$ ipratropium bromide; (d) $200 \mu \mathrm{g}$ ipratropium bromide. The effects of the drug or placebo were assessed by measuring $\mathrm{FEV}_{1}$ and forced vital capacity (FVC) at $-5,0,5,15,30,45,90$ and 120 minutes and hourly thereafter until 480 minutes post-inhalation. The pulse rate was noted at the time points above and blood pressure was noted at $0,60,120$ and 480 minutes. The subjects were asked to volunteer any side effects. This trial was approved by the ethical committee.

The data were analysed using a 3-way, mixed model of variance. Duncan's multiple range test was used to examine any source of variation. Time to peak effect and area under the response curve were analysed. Analysis of area under the response curve allows data biased by unequal time intervals to be assessed.

\section{Results}

One patient withdrew due to nausea and vomiting whilst on the highest dose of ipratropium bromide and all the patients complained that the medication had an unpleasant taste. For the remaining 19 patients, there were no significant differences 
between the baseline values for the 3 treatments or placebo. All three doses of ipratropium bromide produced a significant change in $\mathrm{FEV}_{1}$ compared to placebo at each time point except at 8 hours, $P<0.05$ (Figure 1). The FVC following all three doses of ipratropium bromide differed significantly from values after placebo up to 2 hours postinhalation and up to 6 hours post-inhalation for the highest dose showing a very similar pattern to the $\mathrm{FEV}_{1}$ shown in Figure 1 . The $200 \mu \mathrm{g}$ dose produced a significantly greater $\mathrm{FEV}_{1}(P<0.05)$ than the $40 \mu \mathrm{g}$ dose at all time points, and than the $80 \mu \mathrm{g}$ dose at $0,30,90,180,360$, and 420 minutes post-inhalation. The maximum $\mathrm{FEV}_{1}$ obtained was significantly greater $(P<0.05)$ for the $200 \mu \mathrm{g}$ dose than the $40 \mu \mathrm{g}$ dose though not the $80 \mu \mathrm{g}$ dose. The greatest difference in the mean $\mathrm{FEV}_{1}$ values at any one point was $100 \mathrm{ml}$. We also looked at individual data; in 16 patients there was less than $10 \%$ difference between any of the doses of ipratropium. In 3 patients there were greater than $10 \%$ differences in spirometry after $80 \mu \mathrm{g}$ compared to $40 \mu \mathrm{g}$, and in 2 of them there was a further increase in spirometry of more than $10 \%$ with $200 \mu \mathrm{g}$. There were no significant differences in pulse or blood pressure at any time post-inhalation of ipratropium bromide compared to placebo.

\section{Discussion}

The role of atropine-like drugs as bronchodilators has been recognized since the seventeenth century. The efficacy of ipratropium bromide as a bronchodilator has been widely shown in both asthma and chronic airflow obstruction. ${ }^{10}$ The currently recommended therapeutic dose of this drug is two puffs of $20 \mu \mathrm{g}$ each via a metered dose inhaler although Atrovent forte $(40 \mu \mathrm{g} / \mathrm{puff})$ is available. However, some studies have suggested that a higher dose may be beneficial in terms of duration and peak effect. A small but significant increase in the peak $\mathrm{FEV}_{1}$ of bronchitis was shown after inhalation of a $120 \mu \mathrm{g}$ dose $^{1}$ and similar increase in asthmatics and bronchitics using an $80 \mu \mathrm{g}$ dose ${ }^{4}$ comparing these to the standard regime but without placebo control. Hockley and Johnson documented a small increase in $\mathrm{FEV}_{1}$ and $\mathrm{FVC}$ of chronic asthmatics using $40 \mu \mathrm{g}$ and $100 \mu \mathrm{g}$ doses in placebo controlled study. ${ }^{9}$

In the present study three patients showed an increase in $\mathrm{FEV}_{1}$ of greater than $10 \%$ after inhala-

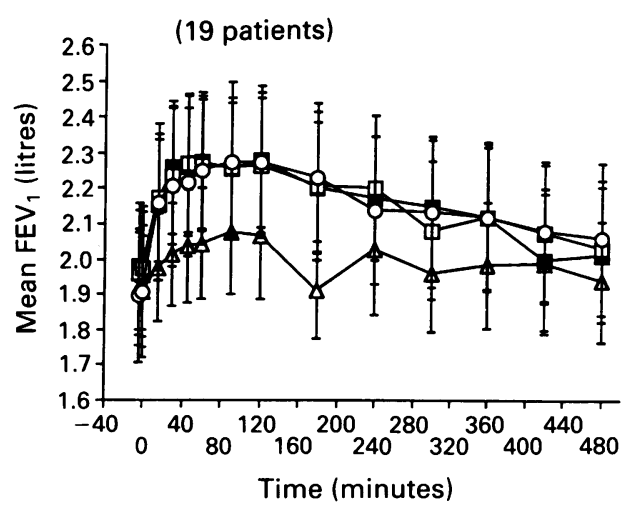

Figure 1 A comparison of the change in $\mathrm{FEV}_{1}$ with time. The vertical lines represent the standard error. $\Delta$, treatment $\mathrm{A} ; \boldsymbol{\square}$, treatment $\mathrm{B} ; \boldsymbol{\square}$, treatment $\mathrm{C}$; $\mathrm{O}$, treatment $\mathrm{D}$.

tion of $80 \mu \mathrm{g}$ and 2 patients showed sequential increases of greater than $10 \%$ with $200 \mu \mathrm{g}$ compared to $80 \mu \mathrm{g}$. All the subjects noted an unpleasant taste with the three drug doses compared to placebo. One patient had to withdraw because of headache and nausea whilst taking the highest dose. However, no abnormality was found on clinical examination and the significance of this incident is questionable.

The data presented confirm that a higher dose than that recommended, of $200 \mu \mathrm{g}$, produced a significantly greater peak effect and duration than either placebo or the standard dose of $40 \mu \mathrm{g}$. However, as in previous studies the actual changes in spirometry were in the order of $100 \mathrm{ml}$ and the clinical significance of such differences remains unclear.

We conclude that ipratropium bromide is an effective bronchodilator agent which produces a greater effect on spirometry when given in higher doses than those currently used most widely. In some patients this may be of clinical significance and these individuals could be identified by repeated spirometry over the initial 2 hours postinhalation of such therapy.

\section{Acknowledgements}

We would like to thank Boehringer Ingelheim for financial support of this study and Miss Annette Skinner for her expert secretarial assistance.

\section{References}

1. Allen, C. \& Campbell, A. Dose response of ipratropium bromide assessed by two methods. Thorax 1980, 35:
137-139.
2. Petrie, G.R. \& Palmer, K.N.V. Comparison of aerosol ipratropium bromide and salbutamol in chronic bronchitis and asthma. Br Med J 1975, 1: 430-432. 
3. Storms, W.W., Dopico, G.A.\& Reed, C.E. Aerosol Sch 1000: an anticholinergic bronchodilator. Am Rev Resp Dis 1975, 111: $419-422$.

4. Hunt, D., MacDonald, G.F., Reilly, P., Plumley, D. \& Kazim, F. Bronchodilator response to several doses of ipratropium bromide in asthmatics and chronic bronchitics. Curr Therap Res 1983, 33: 651-659.

5. Brown, I.G., Chan, C.S., Kelly, C.A., Dent, A.G. \& Zimmerman, P.V. Assessment of the clinical usefulness of nebulised ipratropium bromide in patients with chronic airflow limitation. Thorax 1984, 39: 272-276.

6. Ward, M.J., Macfarlane, J.T. \& Davies, D. A place for ipratropium bromide in the treatment of severe acute asthma. Br J Dis Chest 1984, 79: 374-378.
7. Marini, J.J., Lakshminaryan, S. \& Kradjan, W.A. Atropine and terbutaline aerosols in chronic bronchitis: efficacy and sites of action. Chest 1981, 80: 285-291.

8. Flint, K.C., Hockley, B. \& Johnson, N.McI. A comparison between a combination of ipratropium bromide plus fenoterol in a single metered dose inhaler (Duovent) and salbutamol in asthma. Postgrad Med J 1983, 59: 724-725.

9. Hockley, B. \& Johnson, N.McI. A comparison of three high doses of ipratropium bromide in chronic asthma. $\mathrm{Br} J \mathrm{Dis}$ Chest 1985, 79: 379-389.

10. Mann, J.S. \& George, C.F. Anticholinergic drugs in the treatment of airways disease. Br J Dis Chest 1985, 79: 209-228. 